\title{
Editor's Comments
}

Generally speaking, it could be said that the beginning of a new calendar year announces a time for resolutions, new opportunities, and fresh starts. And, although this particular issue is a little late coming, this particular issue of JTL marks the end of my tenure as Editor and the beginning for its new Editor, Terry Sefton, who has been hard at work on the next issue. Terry, as many of you will know, spearheaded an exciting special issue of JTL last year. I am sure that the journal will continue to thrive under her leadership.

When I agreed to take on the reins of the journal back in the Fall 2006, I saw this as an exciting challenge and opportunity for me to learn more about the "back-end" of a journal. At times, in the those early days, it seemed a little like the Wizard, from Oz, who worked his magic from behind the curtain. Yes, there was much to learn, and there is still much to do to help move the journal forward even more. That said, I am pleased to have had a hand in moving the journal forward, increasing the readership significantly so by moving the journal on-line. Although this was such a monumental task, I found it rather pleasurable "playing around" with the system to establish our current on-line presence. As a result, we have moved beyond a handful of institutional subscriptions to an on-line presence with almost 1500 individuals who have signed up to access the journal for free under the Open Journal Systems (OJS) platform. I wonder what the next phase of the journal will bring?

In this issue, as with many general issues of JTL, we bring a diverse collection of papers from scholars - new, emerging, and established - on a range of topics and issues. Keith Brownlee, Edward Rawana, and Julia MacArthur start the issue with an intriguing look at a strengths-based approach to teaching in elementary schools. In this piece, they present a look at how engaging students and teachers in a dialogue of strengths can affect the culture of a classroom, and even a whole school, to create a positive school environment. Specifically, this article provides an overview of the model, its implementation in a school, including the theory informing the interventions, followed by two brief case studies showing how the model was applied in a classroom. The intervention, we learn, not only transforms the way in which educators interact with students, but it changes the way students perceive themselves and the manner in which they perceive their own potential.

Ashley McRae, a recent graduate from Ashland University's Early Childhood Education, and Jason Brent Ellis, an assistant professor of instructional and assistive technologies in Ashland University's College of Education, follow with a case study on how elementary school children perceive diversity in a homogeneous community, and they analyze how teaching practices can act as an agent to toward and against multicultural pluralism in the classroom. Their findings suggest that early childhood students see physical manifestation of diversity in many ways. Further, they suggest, the hidden curriculum in the way teachers choose to display diversity in the classroom may hold the key to unlocking a more multicultural curriculum.

Three scholars-Kristen Ferguson, Lorraine Frost, and David Hall from Nippising University - present an investigation of predictors of anxiety, 
depression, and job satisfaction in teachers in northern Ontario. They conclude that efforts made to improve workload, student behavior, and employment conditions may lead to reduced stress among teachers and thus lower levels of depression and anxiety. These results may provide guidance for teachers and administrators, as well as inform teacher retention efforts and attempts to improve teacher job satisfaction. Their conclusions derive from data from selfreport questionnaires, factor analysis and multiple linear regression were performed to determine which sources of stress predict stress-related symptoms among teachers and to explore job satisfaction as predicted by: stress, depression, anxiety, years of teaching experience, gender, grade level assignment and position (part-time vs. full-time).

The fourth article to appear in this issue of $J T L$ is a collaboration between Annie Gojmerac, a member of Curriculum Services within the Halton Catholic District School Board, and Lorenzo Cherubini, Associate Professor and Director of the Tecumseh Centre for Aboriginal Research and Education in the Faculty of Education, Brock University, examine an innovative professional development model, that took the form of a Professional Learning Community (PLC), which focused on transformational teaching strategies as a means of professional development to enhance teacher practice and improve student learning. Their paper provides a framework for provincial, district, and school-level administrators to support the underlying values of teachers' professional capacities as collaborative lead learners.

Jennifer Hall, a doctoral candidate and part-time mathematics education professor at the University of Ottawa, presents some of her findings on gender issues in mathematics, from an Ontario perspective. She challenges the perception that gender issues in mathematics have been "solved" and are no longer a relevant and timely issue by providing an overview of gender issues in mathematics in three domains-achievement, attitude, and participation-from the elementary school level to the university level. From her analysis of a number of data sources, she concludes that gender issues persist in developed countries, like Canada. Her conclusions end with a discussion of the implications of the findings and suggestions of possible steps that may be taken to help ameliorate the current situation.

The next piece to appear in this issue addresses Ontario school administrators' perceptions of what makes a "good teacher." Laura Elizabeth Pinto and her colleagues address this matter by investigating the dominant discourses of what makes a good teacher. Further, they examine Ontario's New Teacher Induction Program (NTIP) to see how this program shapes the perceptions of good teachers and good teaching. Following interviews with fortyone school administrators, they present some highlights that show the highly personal nature of perceptions of good teaching and the ways in which Ontario school administrators' perceptions tend to reinforce dominant discourses. The conclusion raises questions about how new teacher induction programs reinforce dominant discourses and raises possibilities to allow for alternate discourses to coexist.

Teachers learn about using silence mostly through teaching experience, which Stephanos Vassilipoulos and Georgios Konstantinidis, a Lecturer at the University of Patras, Greece, and a postgraduate student at Greek Open 
University, respectively, suggest as they aim to expand the scope of the sparse empirical research literature concerning teachers' use of silence. In this paper, the authors present their findings from ninety-six primary school teachers who responded to a survey about their use of silence during a specific event in school and about their general attitudes about using silence in the classroom. Although they report that teachers generally use silence for a variety of reasons, they learn to use silence through the on-going experience of teaching in the classroom. Vassilopoulos and Konstantinidis end by arguing that teacher educators need to continue to systematically investigate the perception and experiences of silence in classroom settings for designing more effective teacher education courses.

The final article in this issue of JTL connects, as the authors Sharen Kucey and Jim Parsons suggest, the past and the present. Specifically, the purpose of this piece is to explore the principles of Assessment for Learning (AFL) in light of John Dewey's writing about the purpose and possibility of education. The authors outline seven assessment for learning strategies and compare these to insights put forth in Dewey's work. As the authors note, although there is far from adequate space to consider all the matches of Dewey's philosophy and the core principles of assessment for learning in this piece alone, they hope their quest for initial commonality might provide curriculum insight for those now working these new pedagogical activities, like the Alberta Initiative for School Improvement (AISI).

On this note, it has been a pleasure hearing from and interacting with a number of international scholars and academics; it is clear that the journal has reached a rather international audience. Further, we have been pleased to see and receive submissions from graduate students and, in some cases, their supervisors. The reach of the journal has truly moved far beyond our wildest expectations. We hope you will continue to support the journal in the many ways that you have and to share with your colleagues and students the work that has been published here in $J T L$.

Darren Stanley

Editor 